\title{
Physical Activity Behavior, Motivational Readiness and Self-Efficacy among Ontarians with Cardiovascular Disease and Diabetes
}

\author{
Sherry L. Grace, ${ }^{1,2,3,5}$ Susan Barry-Bianchi, ${ }^{2}$ Donna E. Stewart, ${ }^{2,3}$ Ellen Rukholm, ${ }^{4}$ \\ and Robert P. Nolan ${ }^{2,3}$
}

This cross-sectional study examined physical activity and its correlates among 355 diabetes, 144 cardiovascular disease, 75 diabetes and cardiovascular disease, and 390 residents with cardiovascular risk factors. Community residents $(N=2566)$ were screened by telephone, and 964 participants completed a self-report survey. Non-diabetes participants participated in a greater range of physical activities $(p<.001)$, more frequently $(p=.013)$. Diabetes participants had lower physical activity readiness and efficacy $(p s<.009)$. In a regression model $(p<.001)$, region and disease, work, marital and smoking status were significant correlates of physical activity frequency. Interventions which increase motivational readiness and efficacy among diabetics are required to prevent and delay complications, particularly in regions with environmental barriers such as cold weather and homogeneous, low-density land use.

KEY WORDS: physical activity; cardiovascular disease; diabetes mellitus; self-efficacy; motivational readiness.

\section{INTRODUCTION}

Physical activity is integral to promoting health and preventing the onset and progression of diseases such as cardiovascular disease and diabetes mellitus (American Diabetes Association., 2002; Brown et al., 2003; Jolliffe et al., 2001; Taylor et al., 2004; Yusuf et al., 2004; Kohl, 2001), including moderateintensity walking or other lifestyle activities (Franco et al., 2005; Duncan et al., 2005, 2003). Despite the negative outcomes associated with inactivity, many people with cardiovascular disease and/or diabetes are sedentary (Dubbert, 2002; Marsden, 1996).
Research has shown that diabetes mellitus requires lifelong self-management through physical activity for increased longevity, quality of life, and functional independence (American Diabetes Association, 2002). These same lifestyle modifications are required in people with cardiovascular disease to prevent a recurrence, but may be more vital for patients with both cardiovascular disease and diabetes who have heightened risk (Smith et al., 2002). While previous research has examined the correlates of physical activity from a demographic to environmental level in non-medical and cardiac rehabilitation populations (Daly et al., 2002; Trost et al., 2002; Mutrie, 1999), diabetics and broader cardiac samples have been under-studied. Moreover, previous research has established that high cardiovascular risk (Clark, 1999; Ruchlin and Lachs, 1999) and perceived health (Booth et al., 2000) are significant correlates of physical activity in non-medical samples, but scant research has explored physical activity correlates across populations at increased cardiovascular disease risk and in poor health, respectively. 
In order to promote physical activity, an examination of the correlates of this behavior is warranted. The purpose of this study was to examine physical activity behavior and its correlates among people with cardiovascular disease, diabetes mellitus, both, or those at an elevated risk of developing these conditions. An examination of established demographic correlates such as sex, age, ethnocultural background, education, and work status (Trost et al., 2002), psychological correlates such as motivational readiness and self-efficacy (Burns et al., 1998; Brawley et al., 2000; Prochaska and Velicer, 1997; Velicer et al., 1990; Conn et al., 2003; Rodgers et al., 2002; Cowan et al, 1997), and environmental correlates such as residence in northern, rural or urban areas (Humpel et al., 2002) was conducted in the context of these chronic conditions. Of particular interest was whether participants with both cardiovascular disease and diabetes mellitus engaged in more physical activity than other participants.

\section{METHODS}

\section{Design and Procedure}

This constitutes a cross-sectional study from a larger randomized controlled trial (Community Outreach Heart Health Risk Reduction Trial). The participating Ontario sites were targeted as regions with increased cardiovascular disease prevalence, increased risk for related hospitalizations, and modifiable risk factor prevalence (Bondy et al., 1999), namely Sudbury and district (northern), Bruce-Grey counties including Owen Sound and Walkerton (rural), and the Greater Toronto Area (urban).

Multimodal recruitment was conducted through several means: self-referral through advertisements and public health units $(n=554 ; 57.5 \%)$, collaboration with family physicians $(n=320 ; 33.2 \%)$, proactive random digit dialing (Potthoff, 1994) within each participating region and setting $(n=79,8.2 \%)$, and worksites and pharmacists $(n=11 ; 0.1 \%)$. Based on a standardized telephone assessment interview and physician referral form, cardiovascular disease risk as defined by the Framingham algorithm was established (Grundy et al., 1999; Wilson et al., 1998). Individuals at elevated risk for cardiovascular disease (i.e. two or more risk factors) were invited to participate. This also included individuals with a diagnosis of atherosclerotic heart disease. Exclusion criteria consisted of: diagnosis of other heart diseases such as valvular disease or cardiomyopathy, atrial fibrillation, or severe congestive heart failure of New York Heart Association (NYHA) class IV (The Criteria Committee of the New York Heart Association, 1994), lack of consenting support from a primary care provider (including nurse-practitioners), residence in an institution, diagnosis of major psychopathology or substance dependence, and significant language comprehension difficulty in English or French. Those who met study criteria and agreed to participate signed a consent form and were invited to the local site, where behavioral and psychological factors were assessed with a self-report questionnaire and where other clinical parameters were also assessed. Ethics approval was obtained for all participating sites.

\section{Participants}

An initial telephone screening was conducted for 2566 participants. Participants were asked to continue to the next phase of the study if they had cardiovascular disease, diabetes, or two or more cardiovascular disease risk factors (i.e. males $\geq 55$ years; females $\geq 60$ years; family history of cardiovascular disease; hypertension; dyslipidemia; current smoker; body mass index $\geq 27$ ). Nine hundred and sixtyfour participants were eligible for the study and consented to participate. Cardiovascular disease status was based on confirmation from two or more of the following: physician report, self report, or prescribed cardiovascular disease medication. Diabetes status was based on confirmation from two or more of the following: physician report, self report, physician reported fasting plasma glucose value greater than seven $\mathrm{mmol} / \mathrm{l}$, or prescribed diabetes medication. Of the participants with diabetes, almost all $(98.7 \%)$ had type 2 diabetes, of which $56.4 \%$ controlled their condition through anti-hyperglycemic medication and $13.1 \%$ through insulin.

Participant characteristics are shown in Table I. In addition to the urban site, there were 311 $(32.3 \%)$ participants from the rural region, and 134 (13.9\%) from the northern region. Distinct cultural communities exist within these participating sociogeographic regions, particularly Afro-Caribbean $(n=30,3.2 \%)$, South Asian $(n=26,2.8 \%)$, Aboriginal $(n=22,2.3 \%)$, and Francophone communities $(n=18,1.9 \%)$. Ages ranged from 35-74. The number of years since diagnosis ranged from .08-53 (mean $5.27 \pm 8.12$ ) for participants with diabetes, 
Table I. Sample Characteristics by Disease Status

\begin{tabular}{|c|c|c|c|c|c|}
\hline Characteristic & CVD $(n=144)$ & $\mathrm{DM}(n=355)$ & $\begin{array}{c}\text { DM \& CVD } \\
(n=75)\end{array}$ & $\begin{array}{l}\text { Neither } \\
(n=390)\end{array}$ & Total $(N=964)$ \\
\hline Sex (\%female) & $48(33.3 \%)$ & $208(58.6 \%)$ & $35(46.7 \%)$ & $217(55.6 \%)$ & $508(52.7 \%)$ \\
\hline Age $($ mean \pm SD) & $63.06 \pm 6.85$ & $56.15 \pm 8.65$ & $61.06 \pm 7.50$ & $58.91 \pm 8.95$ & $58.61 \pm 8.81$ \\
\hline Ethnocultural background (\% white) & $128(88.9 \%)$ & $267(75.2 \%)$ & $55(73.3 \%)$ & $354(90.8 \%)$ & $804(83.4 \%)$ \\
\hline Years of education (mean $\pm \mathrm{SD}$ ) & $12.36 \pm 3.01$ & $13.62 \pm 2.71$ & $13.30 \pm 2.89$ & $14.32 \pm 2.52$ & $13.76 \pm 2.73$ \\
\hline Marital status (\%married) & $110(76.4 \%)$ & $224(63.1 \%)$ & $46(61.3 \%)$ & $277(71.0 \%)$ & $657(68.2 \%)$ \\
\hline Family income ( $<\$ 50,000 \mathrm{CAD} /$ year $)$ & $64(47.4 \%)$ & $154(45.2 \%)$ & $40(59.7 \%)$ & $124(32.9 \%)$ & $382(41.5 \%)$ \\
\hline \multicolumn{6}{|l|}{ Work status } \\
\hline$\%$ Full time & $37(25.7 \%)$ & $136(38.5 \%)$ & $19(25.7 \%)$ & $137(35.1 \%)$ & $329(34.2 \%)$ \\
\hline$\%$ Retired & $75(52.1 \%)$ & $92(26.1 \%)$ & $28(37.8 \%)$ & $141(36.2 \%)$ & $336(35.0 \%)$ \\
\hline Site (\%urban) & $40(27.8 \%)$ & $207(58.3 \%)$ & $29(38.7 \%)$ & $243(62.3 \%)$ & $519(53.8 \%)$ \\
\hline $\begin{array}{l}\text { Framingham Algorithm - absolute risk (mean } \pm \\
\text { SD) }\end{array}$ & $13.27 \pm 5.42$ & $15.86 \pm 8.51$ & $17.50 \pm 8.11$ & $13.37 \pm 6.77$ & $13.14 \pm 8.25$ \\
\hline Body mass index (mean $\pm S D)$ & $29.44 \pm 4.90$ & $32.12 \pm \pm 7.01$ & $32.08 \pm 7.25$ & $29.26 \pm 6.08$ & $30.57 \pm 6.50$ \\
\hline Waist circumference (mean $\mathrm{cm} \pm \mathrm{SD}$ ) & $40.17 \pm 4.86$ & $42.09 \pm 6.13$ & $42.53 \pm 5.98$ & $39.70 \pm 6.15$ & $40.88 \pm 6.06$ \\
\hline Systolic blood pressure (mean mm Hg $\pm \mathrm{SD}$ ) & $126.07 \pm 17.57$ & $126.63 \pm 16.69$ & $130.62 \pm 16.94$ & $126.35 \pm 16.78$ & $126.73 \pm 16.91$ \\
\hline Diastolic blood pressure (mean $\mathrm{mm} \mathrm{Hg} \pm \mathrm{SD}$ ) & $74.92 \pm 9.48$ & $77.41 \pm 9.19$ & $74.70 \pm 10.97$ & $77.43 \pm 10.58$ & $76.83 \pm 9.98$ \\
\hline High density lipoprotein (mean mmol/L \pm SD) & $1.25 \pm 0.38$ & $1.27 \pm 0.39$ & $1.16 \pm 0.38$ & $1.43 \pm 0.46$ & $1.32 \pm 0.43$ \\
\hline Low density lipoprotein (mean mmol/L $\pm \mathrm{SD}$ ) & $2.55 \pm .83$ & $3.00 \pm 1.10$ & $2.54 \pm .96$ & $3.42 \pm .93$ & $3.07 \pm 1.04$ \\
\hline Total cholesterol (mean $\mathrm{mmol} / \mathrm{L} \pm \mathrm{SD}$ ) & $4.48 \pm 1.01$ & $5.32 \pm 1.64$ & $4.70 \pm 1.10$ & $5.67 \pm 1.10$ & $5.29 \pm 1.37$ \\
\hline Triglycerides (mean mmol/L $\pm \mathrm{SD}$ ) & $1.57 \pm .82$ & $2.37 \pm 2.61$ & $2.26 \pm 1.20$ & $1.85 \pm 1.13$ & $2.03 \pm 1.82$ \\
\hline Fasting Plasma Glucose (mean $\mathrm{mmol} / \mathrm{l} \pm \mathrm{SD}$ ) & $5.42 \pm .77$ & $8.47 \pm 3.26$ & $8.36 \pm 3.20$ & $5.33 \pm .68$ & $6.82 \pm 2.76$ \\
\hline Smoking status (\%current) & $11(7.6 \%)$ & $45(12.7 \%)$ & $9(12.0 \%)$ & $68(17.6 \%)$ & $133(13.8 \%)$ \\
\hline
\end{tabular}

Note. CVD: cardiovascular disease; DM: diabetes mellitus.

ANOVA and chi-squares by disease status are all significantly different, $p s<.05$.

and from .08-25 (mean $6.73 \pm 6.30$ ) for participants with cardiovascular disease. As noted, all variables differed significantly by disease status.

\section{Measures}

During the telephone screening, participants were asked to self-report whether they had cardiovascular disease or diabetes, and how many months ago they were diagnosed. Data from primary care physician or nurse-practitioner reports were used to confirm disease status. These reports were also used to abstract other parameters needed to compute the 10 year absolute risk for developing cardiovascular disease based on the Framingham-derived global risk assessment algorithm (Grundy et al., 1999; Wilson et al., 1998). The factors used to estimate risk included age, low density lipoprotein, high density lipoprotein, blood pressure, cigarette smoking, and diabetes mellitus. During the site visit, height and weight (to compute body mass index), waist circumference, and blood pressure were assessed.

Physical activity behavior was evaluated in the survey through items from the 1996 Canadian National Population Health Survey (http://www. statcan.ca/english/concepts/nphs/index.htm). Participants were asked to check each activity in which they had participated in the last three months from a list of 20 activities of varying intensities (i.e., walking for exercise, gardening or yard work, swimming, bicycling, dance, home exercise, ice hockey, ice skating, in-line skating, exercise class or aerobics, bowling, baseball or softball, tennis, weight training, fishing, volleyball, basketball, downhill skiing or snowboarding, golfing, and running or jogging). The total number of activities was computed. Frequency and duration were assessed by asking participants the number of times they engage in these activities per week and the number of minutes they spend engaging in these activities per bout, respectively. Lifestyle physical activity was assessed by asking participants the number of hours they spend in a typical week walking or riding a bike to work or run errands.

\section{Physical activity correlates}

The survey included an assessment of selfreported physical activity correlates at the sociodemographic and psychosocial level. The sociodemographic data included age, sex, ethnocultural 
Table II. Number of Physical Activities (PA), and the Frequency and Duration of Lifestyle Activities by Disease Status

\begin{tabular}{lccccc}
\hline \multicolumn{1}{c}{ PA Parameter } & CVD $(n=144)$ & DM $(n=355)$ & $\begin{array}{c}\text { DM \& CVD } \\
(n=75)\end{array}$ & $\begin{array}{c}\text { Elevated risk } \\
(n=390)\end{array}$ & Total $(N=964)$ \\
\hline Number of activities (mean \pm SD) & $3.17 \pm 1.72^{*}$ & $2.58 \pm 1.74^{*}$ & $2.61 \pm 1.44^{*}$ & $3.39 \pm 2.00^{*}$ & $3.00 \pm 1.86$ \\
Lifestyle PA frequency $(\% \geq 3$ times/wk) & $61(61.6 \%)$ & $153(55.0 \%)$ & $28(57.1 \%)$ & $243(67.3 \%)$ & $485(61.6 \%)$ \\
Lifestyle PA duration $(\% \geq 31 \mathrm{~min} /$ bout $)$ & $93(67.4 \%)$ & $189(57.1 \%)$ & $37(55.2 \%)$ & $247(65.0 \%)$ & $566(61.8 \%)$ \\
\hline
\end{tabular}

Note. CVD: cardiovascular disease; DM: diabetes mellitus.

${ }^{*} p<.05$.

background, marital status, years of education, work status, and income. Participants were also asked if they were current, past, or non- smokers.

Motivational readiness or stage of change for physical activity was assessed with two items, both scored on a six-point scale ranging from 1-"No, I am not at all ready and I believe it is not important for my health," 2-"No, I am not at all ready but I believe it is important to my heart health" to 6-"Yes, regularly for more than 6 months." This scale corresponds with Prochaska's stages of change (Prochaska and Velicer, 1997) from precontemplation (non-believer and believer) to maintenance (Reed, 1999). The first item queried about moderate-to-vigorous exercise intensity for $20 \mathrm{~min}$ 3-5 times per week, and the second item queried about lifestyle activity most days of the week (i.e. keeping active through walking, climbing stairs, cutting grass, shoveling snow, and washing floors). A composite mean score was computed for physical activity stage of change.

Corresponding items were created to assess physical activity efficacy in the domains of moderateto-vigorous exercise intensity and lifestyle activity most days of the week. Participants were asked to rate their confidence in performing these physical activity behaviors on a five-point Likert type scale ranging from 0-"not at all confident" to 4-"extremely confident" (Reed, 1999). Again, a composite mean score was computed for physical activity efficacy.

\section{Statistical Analyses}

Data were cleaned and screened to evaluate statistical assumptions. Statistical analyses were performed with SPSS 14.0. A descriptive examination of the variables was performed, and sociodemographic and clinical differences by disease status were analyzed with chi-square and ANOVAs as appropriate. Logistic regression analysis was used to examine the correlates associated with physical activity frequency. Where significant differences were found, post-hoc non-parametric tests were performed using Games-Howell.

\section{RESULTS}

\section{Self-Reported Physical Activity Type, Frequency and Duration}

The mean number of activities engaged in over three months are shown in Table II, and ranged from zero to 12 . The number of activities differed significantly by disease status $(F(3,955)=13.67, p<.001)$. Post-hoc non-parametric Games-Howell tests revealed that participants with cardiovascular disease engaged in a greater range of activities than those with diabetes $(p=.003)$, and participants with neither cardiovascular disease nor diabetes engaged in a greater range of activities than those with diabetes $(p<.001)$ or those with both cardiovascular disease and diabetes $(p=.001)$. With regards to duration per week engaging in lifestyle activity, $28(2.9 \%)$ participants spent more than $20 \mathrm{~h}, 42(4.4 \%)$ spent from $11-20 \mathrm{~h}, 110$ (11.5\%) spent from 6-10 h, 361 (37.7\%) spent from $1-5 \mathrm{~h}, 224(23.4 \%)$ spent less than one hour, and 192 (20.1) participants spent no time doing so in a typical week.

Typical weekly bout duration of lifestyle activity was zero minutes for 192 participants $(20.1 \%)$, less than $1 \mathrm{~h}$ for 224 participants $(23.4 \%)$, from $1-$ $5 \mathrm{~h}$ for 361 participants $(37.7 \%)$, from $6-10 \mathrm{~h}$ for 110 participants $(11.5 \%)$, from $11-20 \mathrm{~h}$ for 42 participants $(4.4 \%)$, and greater than $20 \mathrm{~h}$ for 28 participants $(2.9 \%)$. Average weekly frequency of lifestyle activity was zero times per week for 83 participants (10.5\%), 1-2 times for 219 participants $(27.8 \%)$, from 3-4 times for 265 participants (33.7\%), from 5-6 times for 140 participants (17.8\%), and 7 or more for 80 participants $(10.1 \%)$. A median split was used to create a dichotomous lifestyle physical activity frequency variable of $\leq$ two times per week versus three or more times per week (Table II). 
Table III. Frequency of Stage of Change for Physical Activity, $N=964$

\begin{tabular}{lcc}
\hline & $\begin{array}{c}\text { Moderate-Vigorous } \\
\text { activity } 20 \mathrm{~min}, 3+ \\
\text { times/wk }\end{array}$ & $\begin{array}{c}\text { Planned lifestyle } \\
\text { activity most } \\
\text { days of the week }\end{array}$ \\
\hline $\begin{array}{l}\text { Precontemplation - } \\
\quad \text { Non-believer }\end{array}$ & $4(0.4 \%)$ & $5(0.5 \%)$ \\
$\begin{array}{l}\text { Precontemplation - } \\
\quad \text { Believer }\end{array}$ & $101(10.7 \%)$ & $50(5.3 \%)$ \\
$\begin{array}{l}\text { Contemplation } \\
\text { Preparation }\end{array}$ & $76(8.0 \%)$ & $50(5.3 \%)$ \\
Action & $278(29.3 \%)$ & $128(13.5 \%)$ \\
Maintenance & $178(18.8 \%)$ & $139(14.6 \%)$ \\
\hline
\end{tabular}

\section{Physical Activity Motivational Readiness and Self-Efficacy}

As shown in Table III, most participants were in the maintenance stage with regard to planned lifestyle activity most days of the week; however they were more frequently in earlier stages with regard to moderate to vigorous physical activity for at least 20 min three or more times per week. Table IV displays the mean physical activity stage of change and self-efficacy scores, and each differed significantly by disease status (readiness for moderate to vigorous activity three times per week $F(3,947)=5.03$, $p=.002$; readiness for planned lifestyle physical activity most days of week $F(3,949)=11.27, p<.001$; efficacy for moderate to vigorous activity 3 times per week $F(3,957)=5.56, p=.001$; readiness for planned lifestyle physical activity most days of week $F(3,953)=8.75, p<.001)$. Games-Howell posthoc tests were conducted to uncover these differences. Motivational readiness for moderate to vigorous physical activity was significantly lower in diabetic participants than cardiovascular disease participants $(p=.007)$ and those with neither condition $(p=.009)$. Motivational readiness for planned lifestyle physical activity most days of the week was also significantly lower in diabetes participants than cardiovascular disease participants $(p<.001)$ and those with neither condition $(p<.001)$. Efficacy for moderate to vigorous physical activity was significantly lower in diabetes participants than cardiovascular disease participants $(p=.01)$ and those with neither condition $(p=.03)$. Additionally, this selfefficacy was higher among participants with cardiovascular disease only when compared to those with both cardiovascular disease and diabetes $(p<.05)$. Efficacy for planned lifestyle physical activity most days of the week was also significantly lower in diabetes participants than cardiovascular disease participants $(p<.001)$ and those with neither condition $(p<.001)$.

Overall, the composite physical activity stage of change score was $3.88 \pm 1.03$, and the composite physical activity self-efficacy score was $3.10 \pm 1.00$. There were no significant correlations among time since diagnosis and motivational readiness or efficacy for those with cardiovascular disease ( $r=-.02$, $p=.83 ; r=-.02, p=.86$, respectively) or diabetes ( $r=-.02, p=.70 ; r=-.09, p=.13$, respectively).

\section{Model of Lifestyle Physical Activity Frequency Correlates}

A logistic regression analysis was conducted predicting weekly frequency of lifestyle activity ( $<$ vs $\geq$ three times per week). Analysis was conducted using SPSS LOGISTIC REGRESSION. A test of the full model with all predictors against a constantonly model was statistically reliable $\left(\chi^{2}(12)=51.98\right.$, $p<.001$ ), indicating that the correlates, as a set, reliably distinguished between those who exercised more frequently than others (Table V). According to the Wald criterion, marital status, work

Table IV. Mean and Standard Deviation of Physical Activity (PA) Motivational Readiness and Efficacy by Disease Status

\begin{tabular}{|c|c|c|c|c|c|}
\hline & $\operatorname{CVD}(n=144)$ & $\mathrm{DM}(n=355)$ & $\begin{array}{c}\text { DM \& CVD } \\
\quad(n=75)\end{array}$ & Neither $(n=390)$ & Total $(N=964)$ \\
\hline $\begin{array}{l}\text { Readiness }^{a} \text { for Moderate-Vigorous PA } 20 \\
\text { min, } 3+\text { times/wk }\end{array}$ & $3.77 \pm 1.35^{*}$ & $3.34 \pm 1.33^{*}$ & $3.50 \pm 1.41$ & $3.64 \pm 1.27^{*}$ & $3.54 \pm 1.33$ \\
\hline Readiness $^{a}$ for lifestyle PA most days/wk & $4.43 \pm 1.00^{*}$ & $3.91 \pm 1.37^{*}$ & $4.14 \pm 1.24$ & $4.36 \pm 1.09^{*}$ & $4.19 \pm 1.22$ \\
\hline $\begin{array}{l}\text { Efficacy for Moderate-Vigorous PA } 20 \\
\text { min, } 3+\text { times } / \text { wk }\end{array}$ & $3.23 \pm 1.15^{*}$ & $2.86 \pm 1.29^{*}$ & $2.73 \pm 1.41^{*}$ & $3.11 \pm 1.11^{*}$ & $3.00 \pm 1.22$ \\
\hline Efficacy for lifestyle PA most days/wk & $3.39 \pm 0.92 *$ & $2.98 \pm 1.18^{*}$ & $3.06 \pm 1.20$ & $3.33 \pm 0.98^{*}$ & $3.19 \pm 1.08$ \\
\hline
\end{tabular}

Note. CVD: cardiovascular disease; DM: diabetes mellitus.

${ }^{*} p<.05$

aReadiness scores range from 1 'precontemplation' to 6 'maintenance'. 
Table V. Model of Physical Activity Frequency Correlates, $N=964$

\begin{tabular}{lrrrrr}
\hline \multicolumn{1}{c}{ Variable } & \multicolumn{1}{c}{$\beta$} & Wald & $p$ & OR & \multicolumn{1}{c}{$95 \%$ C.I. } \\
\hline Sex & -.066 & .162 & .688 & .936 & $.679-1.291$ \\
Age & .020 & 3.822 & .051 & 1.020 & $1.000-1.040$ \\
Ethnocultural background & .069 & .105 & .746 & 1.072 & $.704-1.632$ \\
Marital status & .383 & 5.027 & .025 & 1.467 & $1.049-2.051$ \\
Years of education & .005 & .022 & .883 & 1.005 & $.942-1.072$ \\
Work status & -.509 & 7.876 & .005 & .601 & $.422-.858$ \\
Site - Urban & & 6.290 & .043 & & \\
Site - Rural & -.309 & 2.405 & .121 & .734 & $.497-1.085$ \\
Site - Northern & -.491 & 5.762 & .016 & .554 & $.342-.897$ \\
Smoker & .464 & 3.864 & .049 & 1.591 & $1.001-2.527$ \\
Disease status - Neither & & 6.743 & .081 & & \\
Disease status - CVD & -.308 & 1.447 & .229 & .735 & $.445-1.214$ \\
Disease status - DM & -.439 & 6.182 & .013 & .645 & $.456-.911$ \\
Disease status - CVD \& DM & -.415 & 1.575 & .209 & .660 & $.346-1.262$ \\
\hline Nore CVD:Cardiovascur
\end{tabular}

Note. CVD: cardiovascular disease; DM: diabetes mellitus.

status, smoking, region, and disease status were significant predictors of lifestyle activity frequency. Post-hoc chi-square analyses on the former three variables revealed that married or partnered participants $(64.2 \%)$ were more frequently active than those who were not $\left(56.2 \% ; \chi^{2}=4.63, p=.03\right)$, participants who were employed on a temporary or part-time basis $(66.9 \%)$ were more frequently active than those who were employed fulltime $\left(52.1 \% ; \chi^{2}=16.77, p<.001\right)$, and non-smokers $(63.8 \%)$ were more frequently active than smokers $\left(47.1 \% ; \chi^{2}=10.65, p=.001\right)$. Community type was also significant, whereby northern participants were less frequently active (52.0\%) and urban participants were more frequently active $\left(65.2 \% ; \chi^{2}=7.79\right.$, $p=.02$ ). With regard to disease status, participants with diabetes were less frequently active, with a trend towards more frequent activity in high-risk participants without established cardiovascular disease or diabetes. Finally, there was a trend toward increased physical activity frequency among participants of older age $(t=-4.49, p<.001)$.

\section{DISCUSSION}

Physical inactivity is prevalent and threatens primary and secondary prevention of chronic diseases, yet factors influencing physical activity behavior in medical populations (particularly those with diabetes mellitus) have been neglected in the literature (Dunn, 1993; Mutrie, 1999; Swift et al., 1995). This study explored the multi-level correlates of physical activity, including the theoretical constructs of motivational readiness and self-efficacy, in a diverse community sample of people with cardiovascular disease and diabetes mellitus. Results revealed that participants engaged in an average of three lifestyle activities, and over $60 \%$ of participants engaged in these activities more than 3 times per week for more than 30 min per bout. While this is quite high when compared to data showing the high degree of inactivity (Dubbert, 2002), these results reflect lifestyle activities of varying intensities, which have also proven beneficial (Duncan et al., 2005; Franco et al., 2005). Motivational readiness and self-efficacy were more favorable for lifestyle versus vigorous-intensity activity, suggesting that maintenance of physical activity would be more successful through the promotion of lesser-intensity activity.

Results discouragingly revealed significantly less physical activity behavior among diabetes participants in adjusted analyses, which could be reflected in their decreased physical activity readiness and selfefficacy. While people with diabetes have additional physical activity considerations with regard to glucose levels, poor circulation, foot care, and perhaps obesity, which those with cardiovascular disease or without diabetes may not have, nevertheless lifestyle activity of the frequency and intensity studied herein is universally recommended based on evidence of risk reduction. While there are a paucity of studies stratifying risk factor data by diabetes status, these results corroborate those of Smith et al. who demonstrated significantly lower daily energy expenditures in a population-based community sample of older participants with diabetes versus normoglycemics (of which $22 \%$ had cardiovascular disease (Smith et al., 2002)).

This lower degree of physical activity behavior, readiness, and efficacy among diabetes 
participants may be a manifestation of the complex self-management regimen in the areas of diet, exercise, foot care, blood glucose monitoring, and medication. This may lead to 'diabetes burnout' (Snoek, 2002) due to repeated failure to successfully achieve ongoing glucose control. An international survey demonstrated a high degree of denial and fatalism among people with diabetes, where $40 \%$ perceived that complications will arise no matter what preventive measures they take (Henrichs, H, and International Diabetes Federation-Europe and Lions Clubs International Foundations., 2002). Considering we showed no difference in physical activity based on time since diagnosis, this suggests that the overall burden of self-management in multiple domains may be contributing to inactivity, rather than burnout over time. Previous research has suggested that patients with diabetes do perceive glycemic control and prevention of complications as motivation to engage in physical activity, but identify diabetes -specific physical activity barriers such as fear of reactions from hypoglycemia (Swift et al., 1995).

Other explanations for the lower degree of physical activity behavior in diabetes patients may include lack of physical activity recommendations from health care providers (Marsden, 1996), who may be targeting other factors for risk reduction. Another explanatory construct could be physical activity history, considering the evidence that activity history during adulthood is a significant correlate of physical activity (Clark, 1999). Diabetes develops in the presence of physical inactivity (American Diabetes Association. 2002; Duncan et al., 2003), as does cardiovascular disease (Yusuf et al., 2004), therefore we cannot speculate that participants with diabetes are more likely to have a history of sedentariness causing inactivity than other participants. Finally, given the significant sociodemographic and anthropometric differences in the diabetes versus non- diabetes groups, it is possible that factors such as obesity for example are playing a role. The issue of obesity in particular is a complicating one, as it is for all studies examining diabetes, in that direction of causality cannot be determined (i.e., is it obesity which leads to lower activity or lower activity which leads to obesity). To address this issue, we ran another regression model including body mass index, and the results revealed consistent correlates, with body mass index reaching significance as well. The level of significance for diabetes status fell slightly to $p=.056$. Moreover, even though the participants with diabetes had a significantly higher mean body mass index of 32 , those without diabetes also had a high mean body mass index of 29 , suggesting that obesity per se is not explaining the effect. Further research is necessary to test these speculations, and gain a better understanding of the reasons for inactivity among people with diabetes.

Consistent with previous research (Trost et al., 2002), region of residence and smoking behavior were also significant correlates of physical activity. In particular, our results revealed lower physical activity frequency among northern Ontario-residing participants and greater frequency among urbanites. This could be related to environmental factors such as colder weather, fewer daylight hours, and more homogeneous and lower density land use which serve as a deterrent to walking or biking from home to work or to run errands (Humpel et al., 2002; Frank et al., 2004) seen in northern areas of Canada and other northern nations such as Scotland (Pageot, 1987; Stephens and Caspersen, 1994). Much research now corroborates that mixed land use (i.e. incorporating both residential and commercial properties), and higher density communities with public transportation (i.e. walking to and from stops or stations) as found in urban environments are related to greater physical activity. In fact, these environmental influences on physical activity are addressed in the American Heart Association's recent lifestyle recommendations (Lichtenstein et al., 2006). Previous research is less consistent in findings related to marital and work status (Booth et al., 2000). Our results suggest that in this older and diverse community sample at elevated risk, being married or partnered is related to greater physical activity frequency, as is non full-time work status. This could be due to the greater time availability to devote to such activities. Contrary to previous research (Trost et al., 2002), sex, ethnocultural background, and education level were unrelated to physical activity frequency in adjusted analyses.

The limitations of this study include the crosssectional design, self-report of physical activity behaviors, unknown generalizability, and differences in participant characteristics by disease status. With regard to the former, the study design precludes any inferences of causality or direction of effect. Second, the self-report of physical activity could have led to social desirability biases and thus possible over-reporting of physical activity behavior. However, to the extent that over-reporting may have occurred, it is likely to have happened across groups, and therefore likely not to have contributed to group 
differences. Third, we were unable to discern the generalizability of our sample, and had to exclude potential participants due to lack of physician confirmation of risk factor status, and unwillingness to participate in the larger intervention. Moreover, the generalizability of our finding regarding the environmental correlate of living in a northern region, would only be generalizable to other northern countries. Finally and most centrally, there were significant differences between disease subgroups on all sociodemographic, anthropometric, and physiological variables examined. For instance, the participants with diabetes were more often female, less likely to be married, and less likely to be retired. Therefore, we cannot rule out the possibility that another variable may explain the relationship between disease status and physical activity frequency and efficacy, although we attempted to control for many sociodemographic variables in our model. Moreover, these differences likely reflect typical characteristics seen in these populations. To address these limitations, future prospective research is required with a matched sample of diabetes and cardiovascular disease participants, which utilizes objective measures of physical activity such as activity monitors. Assuming that subsequent research corroborates these findings, future research should also investigate what factors (e.g., burnout, denial, or fatalism) may play a role in lower physical activity behavior among people with diabetes versus cardiovascular disease, or other conditions such as cancer.

In conclusion, people with diabetes mellitus as well as those living in northern regions engage in less physical activity. Although limited randomized controlled trials of physical activity interventions among people at high risk for cardiovascular disease, including cognitive-behavioral techniques and motivational interviewing (Dishman and Buckworth, 1996; Hancock et al., 2005; Marcus et al., 1992; Marcus et al., 1998; Cowan et al., 1997), have shown promising results, we clearly need a more accessible approach to primary and secondary prevention to successfully reach northern residents and meet the needs of people with diabetes. Recent proliferation of chronic disease management programs, such as combined diabetes education and cardiac rehabilitation programs, may provide a useful forum for such interventions, particularly when they reach non-urban populations. Attention to environmental correlates of physical activity behavior and how to overcome them through the use of telephone or home-based interventions is warranted.

\section{ACKNOWLEDGMENTS}

This research was funded by the Heart and Stroke Foundation. S. Grace is supported by the Ontario Ministry of Health and Long-Term Care.

\section{REFERENCES}

American Diabetes Association. (2002). Diabetes mellitus and exercise. Diabetes Care 25: s64-s68.

Bondy, S. J., Jaglal, S., and Slaughter, P. M. (1999). Area Variation in Heart Disease Mortality Rates. Institute for Clinical Evaluative Sciences, Toronto, ON.

Booth, M. L., Owen, N., Bauman, A., Clavisi, O., and Leslie, E. (2000). Social-cognitive and perceived environment influences associated with physical activity in older Australians. Prev. Med. 31: 15-22.

Brawley, L. R., Rejeski, J. W., and Lutes, L. (2000). A groupmediated cognitive-behavioral intervention for increasing adherence to physical activity in older adults. J. Appl. Biobehav. Res. 5(1): 47-65.

Brown, A., Taylor, R., Noorani, H., Stone, J., and Skidmore, B. (2003). Exercise-Based Cardiac Rehabilitation Programs for Coronary Artery Disease: A Systematic Clinical and Economic Review No. Technology Report no. 34). Ottawa, ON: Canadian Coordinating Office for Health Technology Assessment.

Burns, K. J., Camaione, D. N., Froman, R. D., and Clark, B. A. (1998). Predictors of referral to cardiac rehabilitation and cardiac exercise self-efficacy. Clin. Nurs. Res. 7: 147-163.

Clark, D. O. (1999). Physical activity and its correlates among urban primary care patients aged 55 years or older. J. Gerontol. 54(1): S41-S48.

Conn, V. S., Burks, K. J., Pomeroy, S. H., Ulbrich, S. L., and Cochran, J. E. (2003). Older women and exercise: Explanatory concepts. Womens Health Issues 13(4): 158166.

Cowan, R., Logue, E., Milo, L., Britton, P. J., and Smucker, W. (1997). Exercise stage of change and self-efficacy in primary care: Implications for intervention. J. Clin. Psychol. Med. Settings 4(3): 295-311.

Daly, J., Sindone, A. P., Thompson, D. R., Hancock, K., Chang, E., and Davidson, P. (2002). Barriers to participation in and adherence to cardiac rehabilitation programs: A critical literature review. Prog. Cardiovasc. Nurs. 17(1): 8-17.

Dishman, R. K., and Buckworth, J. (1996). Increasing physical activity: A quantitative synthesis. Med. Sci. Sports Exerc. 28(6): 706-719.

Dubbert, P. M. (2002). Physical activity and exercise: Recent advances and current challenges. J. Consult. Clin. Psychol. 70(3): $526-536$.

Duncan, G. E., Anton, S. D., Sydeman, S. J., Newton, R. L. Jr., Corsica, J. A., Durning, P. E., et al. (2005). Prescribing exercise at varied levels of intensity and frequency: A randomized trial. Arch. Intern. Med. 165(20): 23622369.

Duncan, G. E., Perri, M. G., Theriaque, D. W., Hutson, A. D., Eckel, R. H., Stacpoole, P.W. (2003). Exercise training, without weight loss, increases insulin sensitivity and postheparin plasma lipase activity in previously sedentary adults. Diabetes Care 26(3): 557-62.

Dunn, S. W. (1993). Psychological aspects of diabetes in adults. In Maes, S., Leventhal, H., and Johnston, M. (Eds.), International Review of Health Psychology. Wiley, London, pp. 175197. 
Franco, O. H., de Laet, C., Peeters, A., Jonker, J., Mackenbach, J, and Nusselder, W. (2005). Effects of physical activity on life expectancy with cardiovascular disease. Arch. Intern. Med. 165(20): 2355-2360.

Frank, L. D., Andresen, M. A., and Schmid, T. L. (2004). Obesity relationships with community design, physical activity, and time spent in cars. Am. J. Prev. Med. 27(2): 8796.

Grundy, S. M., Pasternak, R., Greenland, P., Smith, S., Jr, and Fuster, V. (1999). Assessment of cardiovascular risk by use of multiple-risk-factor assessment equations: A statement for healthcare professionals from the American heart association and the American college of cardiology. Circulation 100(13): 1481-1492.

Hancock, K., Davidson, P. M., Daly, J., Webber, D., and Chang, E. (2005). An exploration of the usefulness of motivational interviewing in facilitating secondary prevention gains in cardiac rehabilitation. J. Cardiopulm. Rehabil. 25(4): 200206.

Henrichs, H., and International Diabetes Federation-Europe and Lions Clubs International Foundations. (2002). Fatalism, denial common among world's diabetics.

Humpel, N., Owen, N., and Leslie, E. (2002). Environmental factors associated with adults' participation in physical activity: A review. Am. J. Prev. Med. 22(3): 188199.

Jolliffe, J. A., Rees, K., Taylor, R. S., Thompson, D., Oldridge, N., and Ebrahim, S. (2001). Exercise-based rehabilitation for coronary heart disease. Cochrane Database of Systematic Reviews (Online: Update Software), 1, CD001800.

Kohl, H. W., 3rd. (2001). Physical activity and cardiovascular disease: Evidence for a dose response. Med. Sci. Sports Exerc. 33(6 Suppl): S472-S483.

Lichtenstein, A. H., Appel, L. J., Brands, M., et al. (2006). Diet and lifestyle recommendations revision. A scientific statement form the American Heart Association nutrition committee. Circulation 114: 82-96.

Marcus, B. H., Banspach, S. W., Lefebvre, R. C., Rossi, J. S., Carleton, R. A., and Abrams, D. (1992). Using the stages of change model to increase the adoption of physical activity among community participants. Am. J. Health Promot. 6: $424-429$.

Marcus, B. H., Bock, B. C., Pinto, B. M., Forsyth, L. H., Roberts, M., and Traficante, R. M. (1998). Efficacy of an individualized, motivationally tailored physical activity intervention. Ann. Behav. Med. 20: 174-180.

Marsden, E. (1996). The Role of Exercise in the Well-Being of People with Insulin Dependent Diabetes Mellitus: Perceptions of Patients and Health Professionals. Unpublished Ph.D., University of Glasgow.

Mutrie, N. (1999). Exercise adherence and clinical populations. In Bull, S. (Ed.), Adherence Issues in Sport \& Exercise. John Wiley \& Sons Ltd., England, pp. 75-109.

Pageot, J. C. (1987). Obstacles to participation in physical activities of the Canadian elderly population. In Berridge, M. E., and Ward, G. R. (Eds.), International Perspectives on Adapted Physical Activity. Human Kinetics, Champaign, IL.
Potthoff, R. F. (1994). Telephone sampling in epidemiologic research: To reap the benefits, avoid the pitfalls. Am. J. Epidemiol. 139(10): 967-978.

Prochaska, J. O., and Velicer, W. F. (1997). The transtheoretical model of health behavior change. Am. J. Health Promot. 12(1): $38-48$.

Reed, G. R. (1999). Adherence to exercise and the transtheoretical model of behavior change. In Bull, S. (Ed.), Adherence Issues in Sport \& Exercise. John Wiley \& Sons Ltd., England, pp. 19-45.

Rodgers, W. M., Hall, C. R., Blanchard, C. M., McAuley, E., and Munroe, K. J. (2002). Task and scheduling self-efficacy as predictors of exercise behavior. Psychol. Health 17(4): 405-416.

Ruchlin, H. S., and Lachs, M. S. (1999). Prevalence and correlates of exercise among older adults. J. Appl. Gerontol. 18: 341357.

Smith, N. L., Savage, P. J., Heckbert, S. R., Barzilay, J. I., Bittner, V. A., Kuller, L. H. et al. (2002). Glucose, blood pressure, and lipid control in older people with and without diabetes mellitus: The cardiovascular health study. J. Am. Geriatr. Soc. 50(3): $416-423$.

Snoek, F. J. (2002). Breaking the barriers to optimal glycaemic control-what physicians need to know from patients' perspectives. Int. J. Clin. Prac. Suppl. 129: 80-84.

Stephens, T., and Caspersen, C. J. (1994). The demography of physical activity. In Bouchard, C., and Shephard, R. J. (Eds.), Physical Activity, Fitness, and Health: International Proceedings and Consensus Statement. Human Kinetics, Champaign, IL, pp. 204-213.

Swift, C. S., Armstrong, J. E., Beerman, K. A., Campbell, R. K., and Pond-Smith, D. (1995). Attitudes and beliefs about exercise among persons with non-insulin-dependent diabetes. $D i$ abetes Educ. 21(6): 533-540.

Taylor, R. S., Brown, A., Ebrahim, S., Jolliffe, J., Noorani, H., and Rees, K. et al. (2004). Exercise-based rehabilitation for patients with coronary heart disease: Systematic review and meta-analysis of randomized controlled trials. Am. J. Med. 116(10): 682-692.

The Criteria Committee of the New York Heart Association (Ed.). (1994). Nomenclature and Criteria for Diagnosis of Diseases of the Heart and Great Vessels. Little, Brown \& Co., Boston.

Trost, S. G., Owen, N., Bauman, A. E., Sallis, J. F., and Brown, W. (2002). Correlates of adults' participation in physical activity: Review and update. Med. Sci. Sports Exerc. 34(12): 19962001.

Velicer, W., DiClemente, C., Rossi, J., and Prochaska, J. (1990). Relapse situations and self-efficacy: An integrative model. Addictive Behav. 15: 271-283.

Wilson, P. W., D'Agostino, R. B., Levy, D., Belanger, A. M., Silbershatz, H., and Kannel, W. B. (1998). Prediction of coronary heart disease using risk factor categories. Circulation 97(18): 1837-1847.

Yusuf, S., Hawken, S., Ounpuu, S., Dans, T., Avezum, A., Lanas, F. et al. (2004). Effect of potentially modifiable risk factors associated with myocardial infarction in 52 countries (the INTERHEART study): Case-control study. Lancet 364(9438): 937-952. 